\title{
Respect for the person with dementia: fostering greater user involvement in
}

service planning.

by

Maria Lorentzon, PhD, MSc(Econ), BSc(Soc), SRN, SCM

Visiting Senior Fellow,

European Institute of Health and Medical Sciences, University of Surrey,

Guildford, UK.

and

Karen Bryan, PhD, BSc(Hons), Reg MRCSLT.

Professor of Clinical Practice,

European Institute of Health and Medical Sciences, University of Surrey, Guildford, UK.

Address for all correspondence:

Dr M Lorentzon

6 Pilgrim's Close

Palmers Green

London N13 4HX

Tel. 02088869866

e-mail: MariaLorentzon@aol.com 


\section{Abstract:}

Respect for people with dementia and their involvement in service planning is explored, based on selected research publications and policy papers, mainly from the Department of Health and the Alzheimer's Society. This article supports the inclusion of people with dementia care in service planning as part of person-centred care. Necessary adjustments to research methods and ethics committee procedures for gaining informed consent are discussed, as is the importance of ethical policy formation and implementation, in order to achieve person-centred care. This will ensure a high degree of active involvement by people with dementia, enhancing self respect and responding to the needs of this often marginalised population.

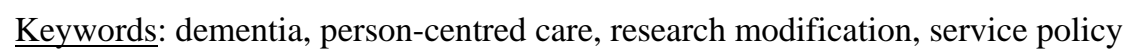


Lack of respect in society was the government's diagnosis of 'UK 2005'. Whenever issues of human behaviour are discussed we tend to think of the average life situation of the average citizen. We often forget older people, and among them, people with dementia. The need for 'person-centred care' is repeatedly stated in government reports and demonstrated in research based evidence. Researchers have provided data to show that one way of supporting people with dementia is to involve them in research and consultation about service planning. Official bodies, whether statutory or voluntary, were fairly slow in providing practical advice on promoting and achieving this care provision. Alzheimer's Society reports in 2000 and 2002 appear cautious about proposing practical methods for increasing involvement by people with dementia. However, the 2003 strategy for 'Living with Dementia' and later documents, show practical commitment to client involvement. There has also been increased Department of Health emphasis on practical participation by people with dementia, co-ordinating various services for seamless service provision (Appleby \& Philip, 2005). Cantley et. al. (2005) describe an inclusive approach to dementia care planning and delivery. In a joint study by Dementia North and Northumbria University, the research team produced a guide 'to explore how people with dementia can be involved in service planning and development' (p. 3). At an international level, the Dementia Advocacy and Support Network International (DASNI) has provided a forum for involving people with dementia in service planning and implementation, which will be discussed below (http://www.dasninertnational.org).

Available evidence, suggesting ways of empowering users to participate in policy formation around services they access, selected research publications and reports from government and voluntary bodies will be examined in this article. The main focus is on the planning of broad systems of services.

\section{Personhood and dignity of people with dementia, and promotion of person-centred care.}

Personhood is central to demand for respect from society and the root of human dignity. Batson et. al.(1994) emphasise ‘a positive sense of self' (p. 15) resulting from life story work among people with dementia. Kitwood (1994) stresses getting inside 'the experience of dementia itself' (p. 12). However, it is important to distinguish between superficial ideology and reality as noted by Brooker (2003): 
The term person-centred care has become all pervasive in the UK dementia care scene. It has been suggested that it has become synonymous with good quality care. It seems that any new approach in dementia care has to claim to be pc (person-centred) in order to be P C (politically correct)..... (p.215).

Likewise Perks et. al (2000) state that ‘despite widespread enthusiasm for such ideas' the shift in emphasis has been rhetorical rather than real. Packer (2000) questions whether person-centred care exists, or whether it is simply an evangelical mission based on 'feckless optimism'(p.4). Perks et. al therefore conclude that implementing person-centred care presents 'a significant challenge' to the methods of communication and consultation with people with dementia. They adopt a person-centred model, building on the work of Goldsmith (1996).

In the next section we discuss adjustments to research methods and the work of ethics committees, needed to achieve maximum involvement in service planning by clients as part of person-centred care.

\section{Adjustments of research methods and ethics committee procedures}

Bryan and Maxim (2006) outline language difficulties associated with dementia and how to manage these. Likewise, many researchers have begun to suggest that successful communication can be achieved by adjusting the environment and having the listener adapt to the individual needs of the person with dementia.

Acknowledging the need to adjust traditional techniques in person-centred research with users of dementia care services, Heiser (2002) conducted a study of views on home-care, using relevant props to represent topics for enquiry. Good (1989) and Barnett (2000) recommend keeping sentences short, avoiding jargon and balancing ‘closed’ and ‘open’ questions. Powell (1994) also suggests using short sentences, which may be repeated if not understood the first time. Respondents must be told clearly at the outset what the interview is about, and it is helpful to address the person by name. During the interview, appropriate pauses should be allowed. Key words can be stressed and memory reminders 
used. Allowance should be made for expression of 'wrong' ideas and words. Farran and KeaneHagerty (1989) also emphasise the need to keep verbal messages clear and concise and concentrate mainly on questions calling for ‘yes/no' answers in questionnaire-based surveys. Modification of time allowance for interviews and size of samples (Barnett, 2000; Wilkinson, 2002) may be appropriate and more unconventional modes of exploring views and feelings of respondents employed, including art, music, drama and life story work.

Haak (2002) observes that the language skills of people with dementia can be enhanced by carers/researchers getting to know them and making them feel more comfortable. Powell (2000) lists carer strategies that can be adopted when people with dementia ask the same questions repeatedly:

- Avoid confrontation: confronting the person with their mistakes is unlikely to help. It creates a negative atmosphere for no benefit.......

- Be practical: It is sometimes possible to anticipate situations that cause problems and to avoid these situations.

- $\quad$ Clarify the feelings and comfort (if anxious or upset): if the person is anxious or upset, telling him ${ }^{1}$ how you think he is feeling may help....(p.19).

However, as well as facilitating communication at an individual level, there is a need to adapt consultative processes, such as committee proceedings and briefing papers, to include people with dementia, so that inclusion constitutes ethical practice. Fredriksson and Erikson (2004) also stress the importance of the 'caring conversation' as part of ethical practice.

DASNI, already referred to above, has provided guidelines for involving people with dementia in research and services planning. The stated intention of this international network of people with dementia, their care partners and professionals is to:

- $\quad$ Promote respect and dignity for persons with dementia.

- $\quad$ Provide a forum for the exchange of information.

\footnotetext{
${ }^{1}$ Non-inclusive language in original.
} 
- Encourage support mechanisms, such as local support groups, counselling groups and internet linkages.

- Advocate for services for people with dementia.

- Assist people to connect with their local Alzheimer's Association. (2006, http://www.dasninertnational.org).

Membership of the network currently includes one third of people with dementia. The National Institute for Clinical Excellence (NICE) has also involved people with dementia in their consultation processes.

Research ethics committees need to institute policies that facilitate obtaining informed consent from people with dementia, rather than arguing that informed consent is not possible. Use of innovative methods such as simplified information and consent sheets and symbolic pictures (Osborne et. al,. 1998) and the criteria for involvement developed by the Stirling Centre (Allan 2001) needs to be more universally sought. McCormack (2002) suggests moving away from 'rational' approaches 'to hear the voice of the person with dementia' (p.114 ), and Blair (1996) stated that 'a mental condition like dementia does not automatically disqualify a patient from giving consent' (p. 61).

We now turn to research evidence supporting greater direct involvement by people with dementia.

\section{Evidence of potential for involvement in research and consultation about services.}

Data derived from using techniques exemplified above may be interpreted differently from those of 'traditional' projects. Nevertheless, the evidence is useful, increasing understanding of the life view and service preferences of the person with dementia. DASNI guidelines for involving people with dementia have been described in the previous section. Allan (2001) explores means whereby staff in various services can encourage users with dementia to express views on the help and support they receive, enabling staff to learn more and support planners of dementia services in consulting users about patterns of care. Echoing themes noted above, Allan emphasises the need to find 'the right word' and 'level'. Work with pictures was found useful and the need to note spontaneous communication, both verbal and non-verbal, while engaged in practical activities, was stressed. 
The following exchange, explicitly expressing desire for dignity and respect by the person with dementia, was conducted between staff member, Gillian, and centre user, Betty:

Gillian: 'And do you like staying in (name of setting) now Betty?

Betty: 'Yes I like it now, but I didn’t like it to begin with.

G: 'Did you not'?

B: ‘Because they were far too strict. You didn't get to use your own mind. And I have a mind of my own'!

G: 'Mmm hmm. And how didn’t they let you use your mind?'

B: 'Oh, I like to use my own mind - what I think, not what other people think. I have a brain of my own.....(p.49).

Practical involvement by people with dementia in researching products and services is demonstrated by Topo et al. (2002) and Orpwood et. al. (2004). Both projects concerned user involvement in investigating telephone usage by people with dementia and whether simplifying the technology would be helpful. The findings indicated that most problems did not disappear with use of the new telephone; 'in most cases it did not help the person to remember whom he ${ }^{2}$ called and when' (Topo et.al, p.390). However, a number of findings on the views of people with dementia did emerge. The researchers concluded that 'people with dementia in day care settings do not consider themselves to be service users in the conventional sense' (ibid.) but stress that it is possible to engage these people in research about their experiences. Importantly, the researchers also noted the importance of considering 'the ethics of undertaking research and accommodating people with dementia' stressing that 'people with dementia are persons first, with views, likes and requirements that co-exist with their illness'(ibid.). Services need to 'devise ways of actively listening to people with dementia on an individual basis and responding imaginatively to what they hear (and)....greater collaboration between interested parties is key to promoting both the emergence of consensus about appropriate strategies for listening and, crucially, the generation of agendas for action’ (p.390 - 391).

\footnotetext{
${ }^{2}$ Non-inclusive language in original.
} 
Summarising policy debate concerning involvement of people with dementia in evaluating the services, Reid et. al. (2001) observe that 'there is currently a growing interest in the idea that people with dementia could have an enhanced role to play in shaping care practice’ (Bond, 1999; Hirst, 1999). This interest can be traced to parallel traits in health and social care practice (Kitwood, 1997) and in considering people with dementia themselves in service development. Cox et. al., (1998) note that 'this trend has emerged alongside a concerted attempt within care settings to eliminate the negative impacts of both environment and staff attitudes on people with dementia' (p. 377-8).

Parker et al. (2001) refer to previous DH/NHS reports, stating that 'quality stands out as the focus of recent government initiative to improve and modernise social and health care services' (DH, 1998; NHS, 2000), commenting that 'performance evaluation for an important component of these drives (DH, 1999; DH/NHS Executive, 1999) relate directly to social care management' (p.28). The authors do, however, observe that often 'performance evaluation is undertaken in an inflexible way, dealing with surface issues rather than the depth of human need and experience' (p.28). They stress the necessity to seek the views of service users. The core question for managers of services is 'can individual older people with dementia define their own quality preferences and priorities in social care services?’ Replying, Parker et. al. suggest reasons for listening to people with dementia, as follows:

- People with dementia can communicate their views, wants and wishes.

- The quality of services may increase with the involvement of service users, in user satisfaction (sic), a decrease in so-called challenging behaviours, and an increase in the job satisfaction of staff.

- The costs of involving social care staff in increased interpersonal and social activity with service users may be outweighed by the gain (p. 30).

In the 'National Service Framework for Older People’ (2001) the Department of Health (DoH) sets out the standard of service quality for people with dementia, stating that 'improving care of older people with depression or dementia depends on providing high-quality, evidence-based care, within this broader framework. Carers of older people with mental health problems may also need information, 
advice and practical help to support them in caring for the older person’ (p. 97). The National Service Framework for Older People stresses that person-centred treatment always involves:

- Explaining the diagnosis to the older person and any carer and where possible giving relevant information about sources of help and support.

- Giving advice about the likely prognosis and packages of care.

- Making appropriate referrals to help with fears and worries, distress, practical and financial issues that may affect the person and their carer.

- At all stages emphasising the unique qualities of the individual with dementia and recognising the personal and social needs (p. 98).

However, no direct advice about increasing involvement by people with dementia in the process of evaluating services is given. The ‘Living with Dementia’ strategy (Alzheimer’s Society, 2003) promotes 'support and involvement of people with dementia as a priority area of work' and various means of achieving this are suggested (Alzheimer's Society, 2003). This strategy was reinforced in a carer's advice sheet (AS, 2005), emphasising the need to make people with dementia feel valued and involved. The 2003 strategy included the following areas of involvement by people with dementia:

- Presentation

- Collecting money for Alzheimer’s Awareness Week

- Video production

- Commenting on government legislation

- Planning social activities

- Recruiting new staff

- Requesting a local support group

- Website design

- Developing information

- Giving views on service

- Sitting in on national board pf trustees

- Attending branch and national AGMs

- Writing article for newsletter 
A future aim was ‘finding ways for people with dementia to be involved in all aspects of the Society's work in a consistent way' (p.3). Cantley et. al. (2005) suggest methods for achieving this, from individual case level to international perspectives, using a number of methods including individual and group consultations, personal or telephone interviews and observation. The authors stress 'real empowerment', noting that 'many existing dementia involvement initiatives have been service initiated, with people with dementia being involved more as "passive suppliers of opinion” as compared to "active negotiators of change” ' (p. 17).

In a later Department of Health policy paper, Appleby \& Philip (2005) provide more suggestions regarding the changing attitudes of service providers, and improving inter-agency collaboration in delivering ‘person-centred’ dementia care. In ‘New Ambition for Old Age’ (2006) the Department of Health reports on the 'next steps in implementing the National Service Framework for Older People'. Stress is placed on the need to combat the 'often negative culture of attitudes towards older people so that they are valued and respected' (DH, 2006, p. 2). The need to involve older people more in care planning is emphasised, and this must extend to those who are living with dementia.

\section{$\underline{\text { Discussion; Maintaining dignity and respect }}$}

Research literature provides data to support greater empowerment of people with dementia provided that adjustment to research and consultation techniques are undertaken. There is evidence that those consulted want more power over decision making concerning their lives and the services they need. Facilitating such involvement to the limit of the ability demonstrated by each individual contributes to the maintenance of dignity and self respect. Allan (2001) shows clear evidence of this in her research discussed above. In conversation between Linda (staff) and Arthur (centre user), the latter indicated that he preferred to ‘struggle on’ rather than to ask for help (p.57) and in the discussion between Wendy (staff) and Peggy (centre user), the latter expressed satisfaction about being given freedom to make decisions, saying: ‘I can please myself, nobody interferes with me’ (p. 57). Reid et. al. (2001) demonstrated similar evidence from research with day care attenders. Frank, a centre user, liked being given 'authority’ which he considered ‘flattering' (p. 385). 
However, there would appear to be a fairly slow official response to research findings and cautious attitudes to real empowerment of people with dementia, with evidence of some discordance between ideology and practice. Cheston et. al (2000) note that 'lowered expectations lead to lower performance and high dependency'. The outcome is that 'the person is gradually disempowered' (p.478).

There are, however, real signs of increasing awareness of the need to involve people with dementia more directly on the part of both the Department of Health and the Alzheimer's Society in the 'Living with Dementia' strategy. Further culture change is needed in order to increase active involvement by people with dementia in decision making about service provision within the NHS and the independent care sector. Negative attitudes to older people, including those who are living with dementia, are in evidence, but government commitment to reducing these is increasingly apparent (DH, 2006).

Evidence of joint working between service agencies as advocated by Appleby \& Philip (2005) and Cantley et. al. (2005), and greater direct involvement by people with dementia in policy formation is already apparent and will, hopefully, increase over time with continued facilitation by the relevant agencies. 


\section{$\underline{\text { References }}$}

1. Allan, K. (2001) Communication and consultation - Exploring ways for staff to involve people with dementia in developing services. Bristol: Joseph Rowntree Foundation, Policy Press.

2. Alzheimer Scotland. (2000) Putting quality first: the need to improve long-stay care for people with dementia.http://www.alzscot.org.uk/policy/longstaysum.html.

3. Anon. (2002) Let's make it happen: The National Service Framework for Older People. London: Alzheimer’s Society.

4. Alzheimer's Society. (2003) Living with dementia - Future strategy. London: Alzheimer’s Society.

5. Alzheimer's Society. (2005) Carers' Advice Sheet: Understanding and respecting the person with dementia. London: Alzheimer’s Society.

6. Appleby, L. \& Philip, I. (2005) Securing better mental health for older adults. Department of Health http://www.dh.gov.uk.

7. Batson, P. Thorne, K. \& Peak, J. (2002). Life story work sees the person beyond the dementia. Journal of Dementia Care 10(3), 15-17.

8. Bond, J. (1999) Quality of life for people with dementia: approaches to the challenge of measurement. Ageing \& Society 19, 561-79.

9. Brooker, D. (2003) What is person-centred care in dementia? Reviews in Clinical Gerontology 13(3): 215-22.

10. Bryan, K. \& Maxim, J. (2006) Communication Disability in the dementias. Chichester: Wiley.

11. Cantley, C. Woodhouse, J. \& Smith, M. (2005) Listen to us: Involving people with dementia in planning and developing services. Dementia North/Northumbria University.

12. Cheston, R., Bender, M. \& Byatt S (2000) Involving people who have dementia in the evaluation of services: A review. Journal of Mental Health 9(5), 471-9.

13. Cox, S., Anderson, I., Dick, S. \& Elgar, J. (1998) The Person, the Community and Dementia: Developing a value framework. Stirling, Dementia Services Development Centre.

14. Dementia Advocacy and Support Network International (DASNI) (accessed 18 October, 2006) (http://www.dasninertnational.org)

15. Department of Health. (1998) Modernising Social Services. London: HMSO. 
16. Department of Health/NHS Executive. (1999) A New approach to Social Services Perfomance. London: DH/NHSE.

17. Department of Health/NHS Executive. (1999) The NHS Performance Assessment Framework. London: DH/NHSE

18. Department of Health. (2001) Modern Standards and service models: Older PeopleNational Service Framework for Older People. DH (http://www.dh.gov.uk)

19. Department of Health (2006) A New Ambition for Old Age - Next steps in implementing the National Service Framework for Older People, London: DH.

20. Fredriksson L \& Eriksson K (2003) The ethics of the caring conversation, Nursing Ethics, $10(2), 138-148$.

21. Hirst, J. (1999) Point of contact. Community Care, Issue 1281: 22-24

22. Goldsmith, M. (1996) Hearing the voice of people with dementia. London: Jessica Kingsley.

23. Haak, N. J. (2002) Maintaining connections: understanding communication from the perspective of persons with dementia. Alzheimer's Care Quarterly, 3(2), 116 - 28.

24. Kitwood, T. (1994). Lowering our defences by playing the part. Journal of Dementia Care, 2(5), 12-14.

25. Kitwood, T. (1997) Dementia reconsidered: the person comes first, Buckingham: Open University Press.

26. NHS Executive. (2000) The NHS Plan: A plan for investment. A plan for reform. Cm 4818-1. London: HMSO.

27. Packer, T. (2000) Does person-centred care exist? Journal of Dementia Care 8(3), 19-21.

28. Parker, J., Pendale, B., Manthorpe, J. \& Bradley, G. (2001) Hearing what users say: The importance of training for high quality management in dementia care. Managing Community Care 9(6), 28-33.

29. Perks, A., Nolan, M., Ryan, T., Enderby, P., Hemmings, I. \& Robinson, K. (2001) Breaking the mould: developing a new service for people with dementia and their carers. Quality in Ageing 2(1), 3-11.

30. Powell, J. (2000) Care to communicate: helping the older person with dementia. London: Hawker Publications Ltd. 
31. Reid, D., Ryan, T. \& Enderby, P. (2001) What does it mean to listen to people with dementia? Disability \& Society, 16(3), 377-92.

32. Wilkinson, H. (2002) The Perspective of People with Dementia, London: Jessica Kingsley Publishers.

33. Wilkinson, H. \& Milne, A. (2003) Sharing a diagnosis of dementia - Learning from the patient perspective. Aging and Mental Health 7(4), 300-7. 